\title{
TINGKAT KEPUASAN IBU HAMIL TERHADAP PELAYANAN ANTENATAL
}

\author{
Rosmeri br bukit \\ Dosen Akademi Kebidanan Dharma Husada Pekanbaru \\ Kampus Pekanbaru Riau Indonesia \\ Email : rosmeribrbukit@gmail.com
}

\begin{abstract}
Satisfaction is the level of one's feelings after comparing the permance perceived outcome with expectations. This research uses a quantitative with descriptive research design. The population in this study were all pregnant women antenatal checkups. Sample in this research were 30 respondents using technigues accidental. Analysis technique used is a univariate analysis. Based on the results obtained from the charging questioner satisfaction rate of pregnancy antenatal di Klinik Pratama Tangor Medical Centre (TMC) Pekanbaru found that the majority of the 30 respondent are satisfied as many as 21 people (70\%). For Tangor Primer Klinik Medical Centre Pekanbaru complete room amenities approprite service standards for code of conduct applicable and treatment costs are covered by the patient.
\end{abstract}

Keywords: Satisfaction, Pregnancy, Antenat

\section{PENDAHULUAN}

Angka Kematian Ibu (AKI) masih merupakan salah satu masalah utama dibidang kesehatan ibu dan anak. AKI berdasarkan Survey Demografi Kesehatan Indonesia (SDKI) tahun 2012 sekitar 228 per 100.000 kelahiran hidup. Sedangkan Angka Kematian Bayi (AKB) 32 per 1000 kelahiran hidup. Angka ini masih tinggi jika dibandingkan dengan negara lain di Asia Tenggara. Target penurunan AKI diindonesia secara global pada tahun 2020 adalah 150 per 100.000 kelahiran hidup, sedangkan AKB 15 per 1000 kelahiran hidup (Walyani, 2015).

Faktor penyebab langsung kematian ibu di Indonesia masih didominasi oleh perdarahan, eklampsia, dan infeksi. Kematian ibu atau maternal mortality, merupakan salah satu indikator dari kesejahteraan suatu bangsa. hal ini karena apabila ditinjau dari penyebabnya, kematian ibu merupakan suatu permasalahan yang kompleks. Penyebab kematian ibu Perdarahan (42\%) Eklampsi /Preeklampsi (13\%) Abortus (11\%) Infeksi (10\%) Partus lama/persalinan macet (9\%) Penyebab lain (15\%) (Kemenkes 2015).

Salah satu upaya dalam penurunan angka kematian tersebut adalah pelayanan kesehatan maternal dan neonatal yang berkualitas dekat dengan masyarakat difokuskan pada tiga pesan kunci Making Pregnancy Saver yaitu pertolongan persalinan oleh tenaga kesehatan, penanganan komplikasi obstetrik dan neonatal, serta pencegahan kehamilan tidak diinginkan dan penanganan komplikasi abortus (Sarwono, 2011).

Untuk dapat memberikan pelayanan kesehatan maternal dan neonatal yang berkualitas dibutuhkan tenaga kesehatan terampil yang didukung tersedianya sarana dan prasarana yang memadai dalam memberikan pelayanan kesehatan kepada ibu dan anak. Kementrian Kesehatan telah memberikan wewenang kepada bidan melalui keputusan menteri kesehatan nomor 1464/Kemenkes/x/2010 tentang registrasi dan praktek bidan. Kewenangan tersebut harus ditindak lanjuti dengan peningkatan kemampuan untuk dapat melaksanakan tugas dengan baik. Bidan yang berkualitas akan mampu melaksanakan deteksi dini resiko tinggi pada saat melaksanakan pelayanan antenatal, mampu memberikan pelayanan gawat darurat pada ibu dan bayi, serta mampu merujuk pasien bila tidak dapat menangani serta diluar batas kewenangannya (Indra, 2011).

World Health Organization (WHO), melakukan suatu pertemuan konsultasi regional Asia Tenggara pada tahun 2014, disepakati bahwa kualitas pelayanan kebidanan yang diberikan kepada setiap ibu yang memerlukannya perlu diupayakan agar memenuhi standar tertentu 
agar aman dan efektif. Pelayanan berkualitas dapat dikatakan sebagai tingkat pelayanan yang memenuhi standar yang telah ditetapkan. Dengan demikian, standar penting untuk pelaksanaan, pemeliharaan dan penilaian kualitas pelayanan (Taufan, 2014).

Untuk itu, kinerja bidan yang optimal sangat dibutuhkan dalam mencapai standar pelayanan yang berkualitas dan prima. Pelayanan kebidanan yang berkualitas adalah pelayanan kebidanan yang sesuai dengan tingkat kepuasan rata-rata penduduk, serta yang penyelenggaraannya sesuai dengan kode etik dan standar pelayanan profesi yang telah ditetapkan. Kepuasan adalah tingkat perasaan seseorang setelah membandingkan kinerja atau hasil yang dirasakan dengan harapannya. (Saifuddin, 2012).

\section{METODOLOGI PENELITIAN}

Jenis penelitian adalah kuantitatif, rancangan deskriptif. Populasi keseluruhan atau totalitas objek yang di teliti yang ciri-cirinya akan di duga atau di taksir (Nasir dkk, 2011). Populasi seluruh ibu hamil yang melakukan Kunjungan Antenatal di Klinik Pratama Tangor Medical Centre (TMC) Pekanbaru dan sampel sebanyak 30 orang pada bulan Oktober - 10 November 2016. Sampling dalampenelitian digunakan accidental Sampling dan analisis univariat .

\section{HASIL DAN PEMBAHASAN}

Distribusi Frekuensi Responden Tentang Tingkat Kepuasan Ibu Hamil Tentang Pelayanan Antenatal

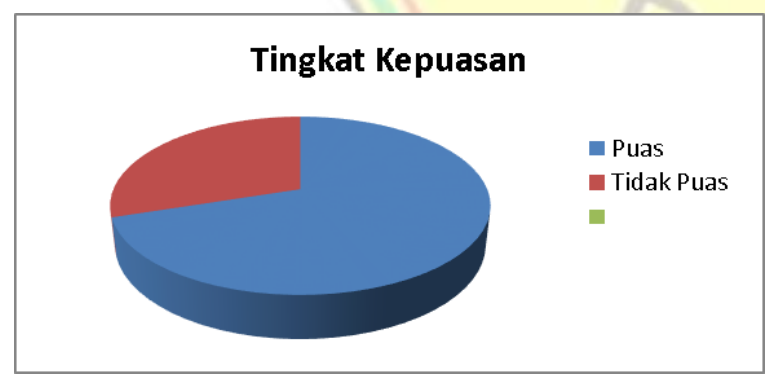

Gambar 1. Analisis Univariat

Hasil penelitian yang telah diperoleh bahwa tingkat kepuasan terhadap 30 responden tentang pelayanan Antenatal di Klinik Pratama Medikal Center Pekanbaru secara keseluruhan mayoritas puas dengan pelayanan yang di berikan berjumlah 21 orang merasa puas (70\%). Jumlah skor yang paling tinggi dapat dilihat dari master tabel bahwa kepuasan pasien terdapat pada keandalan dan keterampilan bidan dalam memberikan pelayanan. Dan ketidakpuasan pasien terdapat pada fasilitas dan biaya pelayanan antenatal yang diberikan bidan.

Menurut (Priyoto, 2014) Kepuasan adalah perasaan senang atau kecewa seseorang yang muncul setelah membandingkan antara persepsi atau kesan terhadap kinerja atau hasil suatu produk dan harapan-harapan nya. Jadi kepuasan merupakan fungsi dari persepsi atau kesan atas kinerja dan harapan jika kinerja di bawah harapan, maka pelanggan tidak puas. Jika keterampilan dan keadalan kinerja memenuhi harapan maka pelanggan akan puas. Jika kinerja melebihi harapan maka pelanggan akan amat puas atau senang. Kunci untuk menghasilkan kesetiaan pelanggan yaitu dengan memberikan nilai pelanggan yang tinggi.

Asumsi peneliti Dilihat dan hasil penelitian diatas Klinik Pratama Medikal Center (TMC), yang mengatakan puas sesuai dengan harapan responden di dorong oleh pelayanan yang di berikan yang bagus, sifat peduli yang di tunjukan petugas, cara komunikasi yang mudah di mengerti, cepat dan tanggap dalam memberikan pelayanan sehingga kinerja memenuhi harapan. Sedangkan responden mengatakan tidak puas fakta yang di temukan saat dinas di Klinik TMC bahwa yang melayani pasien secara langsung bukan bidan Henni tapi mengandalkan petugas lain atau asistennya, di lihat dari jawaban responden mengenai fasilitas yang di sediakan seperti ruangan pemeriksaan ibu hamil sama dengan ruangan pemeriksaan pasien umum, kamar mandi ruangan Intranatal digabung dengan ruangan pasien rawat inap. Dan mengenai biaya yang tidak sama dengan ekonomi responden.

\section{KESIMPULAN DAN SARAN}

Tingkat kepuasan responden tentang Pelayanan Antenatal di Klinik Pratama Medical Centre (TMC) Tahun 2016 adalah mayoritas puas sebanyak 21 orang (70\%). Saran bagi Klinik Pratama Tangor Centre (TMC) Pekanbaru, lengkapi fasilitas ruangan standar pelayanan 
sesuai kode etis yang berlaku dan biaya pengobatan yang terjangkau oleh pasien.

\section{DAFTAR PUSTAKA}

Al-assaf, (2009). Mutu Pelayanan Kesehatan. Jakarta : Medikal Book.

Ari Sulistywati,(2009). Asuhan kebidanan pada masa kehamilan. Jakarta : Salemba Medika.

Abdul Bari Saifuddin, (2006). Buku acuan Nasional Pelayanan Kesehatan Maternal dan Neonatal. Jakarta : Yayasan Bina Pustaka.

Kotler, (2012) prinsip-prinsip pemasaran. Jakarta : Erlangga.

Muninjaya, (2010) Manajemen Rumah Sakit. Jakarta : EGC.

Nasir Abdul, (2011). Metodologi Penelitian Kesehatan. Yogyakarta : Mulia Medika.

Nugroho Taufan, (2014). Askeb 1 Kehamilan. Yogyakarta : Medikal Book.

Notoatmodjo, (2010). Metologi Penelitian Kesehatan. Jakarta : PT Rineka Cipta.

Prawirohardjo Sarwono, (2011) Ilmu Kandungan Edisi keempat. Jakarta : PT Bina Pustaka.
Pudiastuti dewi, (2012). Asuhan kebidanan pada hamil normal dan patologi. Yogyakarta : Nuha medika.

Rismalinda, (2015). Asuhan Kebidanan Kehamilan. Jakarta : $\mathrm{Cv}$ Trans Info Media.

Rukiyah, (2014). Asuhan kebidanan kehamilan kurikulum berbasis kompetensi. Jakarta : CV Trans Info Media.

Saifuddin Aswar, (2012). Sikap dan Perilaku dalam Kesehatan. Jakarta : EGC.

Supranto,(2011) Pengukuran Tingkat Kepuasan Pelanggan. Jakarta : Rineka Cipta.

Tjiptono,(2010).Strategi Pemasaran. Yogyakarta : Graha Ilmu.

Umusu. (2010). Kti diakses pada tanggal 05 April 2016 pukul 15.00 WIB Https://.www.goele.Com/Search?q=kti+ tingkat+kepuasan + pasien + terhadap $+p$ elayanan \&ie $=u t f-8 \& o e=u t f$.

Walyani Siwi, (2015). Asuhan kebidanan pada kehamilan. Yogyakarta : Pustaka Berup Ress.

Yani Indra, (2011). Mutu pelayanan kebidanan. Bandung : Renaka ciipta 